\title{
Effect of fractional crystallization on composition and thermal characteristics of avocado (Persea americana) butter
}

\begin{abstract}
Fractionation of plant butters like avocado (Persea americana) may yield useful fat derivatives with distinct physical and functional properties. In this study, avocado butter was sequentially crystallized in acetone at $5{ }^{\circ} \mathrm{C}(2 \mathrm{~h}), 0{ }^{\circ} \mathrm{C}(24 \mathrm{~h})$, and $\mathrm{i} 20{ }^{\circ} \mathrm{C}(24 \mathrm{~h})$ until the mother-liquor becomes devoid of any crystal formation. The high-melting stearin isolated at $5{ }^{\circ} \mathrm{C}$ and low-melting olein isolated at $\mathrm{i} 20^{\circ} \mathrm{C}$ were compared with the original sample in terms of fatty acid and triacylglycerol (TAG) compositions and thermal profiles. With respect to the original sample, low-melting olein is possessed with higher proportions of diunsaturated and triunsaturated TAG while high-melting stearin is found to become enriched with disaturated and trisaturated TAG molecules. These differences in compositions make the basic physico-chemical parameters as well as the thermal profiles of high-melting stearin and low-melting olein to be distinctly different from those of the original sample.
\end{abstract}

Keyword: Avocado butter; Fractional crystallization; Differential scanning calorimetry (DSC) 